\title{
A Lousa Digital no ensino de Matemática: análise das interações docentes
}

\author{
Interactive Blackboard on Mathematics Teaching: an analysis of teaching interac- \\ tions \\ Pablo Charles de Oliveira Melo \\ Verônica Gitirana \\ Universidade Federal de Pernambuco \\ Universidade Federal de Pernambuco \\ profpablo.charlesmelo@gmail.com \\ veronica.gitirana@gmail.com
}

\begin{abstract}
Resumo Este artigo discute alguns resultados de uma pesquisa de mestrado que buscou analisar a atividade docente com o uso da Lousa Digital para o ensino da Matemática, tomando o ensino de Razão e Proporção, com um olhar para as interações docentes. O estudo teve por base as Pesquisas em interação e interatividade e a teoria da atividade. A investigação procedeu-se por meio de um estudo de um caso de professor de matemática experiente com o uso da Lousa Digital, contando com um total de 130 interações analisadas a luz da análise de conteúdos. Os resultados apontam para uma forte presença da Lousa Digital nas interações relativas a mediações didáticas. No entanto, essas foram mais focada em trazer exemplos, usando a Lousa como um projetor. A perspectiva de quadro interativo foi menor. Essa aparece mais nos momentos em que o professor tem que responder a dúvidas do aluno. Observou-se também uma barreira para aluno interagir com a Lousa Digital diretamente nela, por parte do docente. Por fim, o estudo revelou muitas possibilidades de uso, porém um longo caminho a percorrer para o uso dessa mídia no sentido da convergências de mídias.
\end{abstract}

Palavras-Chave: Lousa Digital, Interação e interatividade, Tecnologia e educação Matemática, razão e proporção.

\begin{abstract}
This paper discusses some results of a MSC research aiming to analyse teaching activity using Interactive blackboard on mathematics class, specifically on ratio and proportion, a teaching interaction analysis. The theoretical framework were based on the literature on interaction and interactivity and on the theory of activity. A case study within an expertise mathematics teacher class using an interactive blackboard was undertaken. His class was recorded and 130 interaction were analysed considering the content analysis perspective. The results pointed out a strong presence of the interactive blackboard in the interaction aiming didactic mediations. Nonetheless, these interactions focused on bringing examples into class as a media projector use. Meanwhile its use in the perspective of an interactive blackboard was smaller. This use was more present when teacher had to answer pupils doubt. A barrier on allowing students to use the interactive blackboard directly was observed. Finally, the study revealed some possibilities but also a long way toward a use of this media in the sense of the convergence of medias.
\end{abstract}

Keywords: Interactive blackboard, interaction and interactivity, technology and Mathematics Education, ratio and proportion. 


\section{Introdução}

Este artigo discute resultado de uma pesquisa de mestrado que investigou a atividade docente com o uso da Lousa Digital para o ensino da Matemática, tomando o ensino de Razão e Proporção, com um olhar para as interações docentes. Nessa pesquisa, a Lousa Digital é defendida na perspectiva da convergência de mídias no ensino presencial, modalidade em que o quadro foi, e ainda é, uma das ferramentas de sala de aula que o professor utiliza para interagir com a turma.

Nakshima e Amaral [1] argumentam que a Lousa Digital possui características que agregam linguagens audiovisuais comparáveis ao rádio, à TV e ao computador, podendo trazer para a sala de aula, a partir de processos comunicativos, um ambiente interativo.

Os estudos sobre o uso da Lousa Digital como recurso didático começaram no Reino Unido no fim da década de 90. Esses estudos relataram os primeiros usos no ensino, em particular o da Matemática, em situações nas quais os recursos digitais eram escassos até mesmo em países ricos. Ao professor, não basta apenas ter a Lousa Digital a sua disposição no contexto da sala de aula, é necessária a apropriação didática dos seus recursos e dos recursos digitais associados. Essa última apropriação, por sua vez, demanda o desenvolvimento de estudos, abordagens e materiais de apoio, o que implica uma diminuição ainda maior na velocidade da apropriação didática.

Se, por um lado, as novas mídias e interfaces são apontadas como promessas para a melhoria do ensino e da aprendizagem quando da inserção dessas ferramentas em sala de aula, por outro, pesquisas são necessárias para se entender os reais avanços e as verdadeiras mudanças nas práticas docentes.

Do ponto de vista do uso da Lousa Digital em sala de aula, por exemplo, há uma ampliação do processo de experimentação e potencialidades de objetos midiáticos, como softwares educativos para a aprendizagem da matemática. Objetos esses que a muito vem sendo investigado. Segundo Kaput [2], essas novas tecnologias trazem a possibilidade de manipulação de objetos no qual a representação que antes era estática passa a ter caráter dinâmico e que isso tem reflexos nos processos cognitivos, particularmente no que diz respeito às concretizações de operações mentais. Além disso, um mesmo objeto matemático passa a ter representações variadas, diferentemente da representação estática das instâncias físicas tipo "lápis e papel" ou "giz e quadro-negro". Gitirana [3], por exemplo, aponta, como uma das potencialidades dessa mídia o estudo de funções, em que a variável de entrada (x) pode ser continuamente arrastada, permitindo que o estudante observe o comportamento de sua imagem $\mathrm{f}(\mathrm{x})$ e observe, ainda, a relação de crescimento/decrescimento entre as variáveis.

Apesar das potencialidades dessa convergência de mídias, os benefícios do uso da Lousa Digital são foco de poucos estudos no Brasil e, mais particularmente no ambiente de sala de aula, na prática de um professor de matemática fazendo uso da Lousa Digital. Nesse contexto, esta pesquisa analisou a atividade docente em sala de aula de matemática com o uso da Lousa Digital. Como um primeiro estudo, optamos pelo estudo exploratório de um professor, tido como bom usuário da Lousa Digital. Optamos pelo estudo de caso. O tema matemático foi, portanto, definido a partir do conteúdo ministrado pelo professor, no caso razão e proporção, em situação normal de sala de aula. Essa aula foi estudada por meio de uma perspectiva das interações docentes, para levantar indícios e responder às seguintes questões:

- Que tipos de interações os recursos da Lousa Digital proporcionam ao ensino de Razões e Proporções?

- Com quais objetivos docentes a Lousa Digital é utilizada?

- Como os recursos da Lousa Digital interferem nas mediações didáticas em sala de aula?

- Como as interações, mediadas pelo uso da Lousa Digital, ocorrem?

- Como o uso da Lousa Digital pode ajudar ou prejudicar as interações?

Temos como hipótese que o uso da Lousa Digital no ensino da matemática favorece as mediações didáticas, por trazer para a sala de aula as potencialidades desenvolvidas nos ambientes digitais já desenvolvidos, como software educacional, vídeo, foto, jogo digital, dentre outros, por meio da convergência de mídias.

Este artigo está estruturado em seis sessões: na próxima, a Lousa Digital é discutida quanto a questões técnicas e inserção no ensino de matemática. Na terceira sessão um breve estudo de interação e interatividade com uso da Lousa Digital e o saber matemático. Na quarta sessão a metodologia adotada na pesquisa. $\mathrm{Na}$ quinta sessão a análise dos resultados. Na última sessão as considerações finais.

\section{A Lousa Digital}

A Lousa Digital (quadro interativo, e-board, whiteboard, lousa eletrônica) trata-se de um dispositivo em que as imagens do computador são projetadas em um quadro, e o usuário interage com o computador por meio de ações diretas na imagem projetada. Nesta projeção, é possível interagir com todos os recursos disponíveis no computador apenas com um toque de caneta ou dos dedos, depen- 
dendo da versão disponível. O incremento cada vez maior desta ferramenta como recurso educacional, principalmente na Europa, conjuntamente à crescente velocidade com que a tecnologia vem avançando, levou ao rápido desenvolvimento de vários modelos de Lousa Digital. A Lousa Digital utilizada em nossa pesquisa foi a Lousa Digital Interativa Tátil. Este modelo permite que o professor interaja com a própria ferramenta, tocando na tela com os dedos ou um objeto que simule caneta, necessitando, para isso, de um quadro fixo com sensores que captem o toque na tela a partir da projeção. Neste artigo, utilizaremos apenas o termo Lousa Interativa a partir de agora.

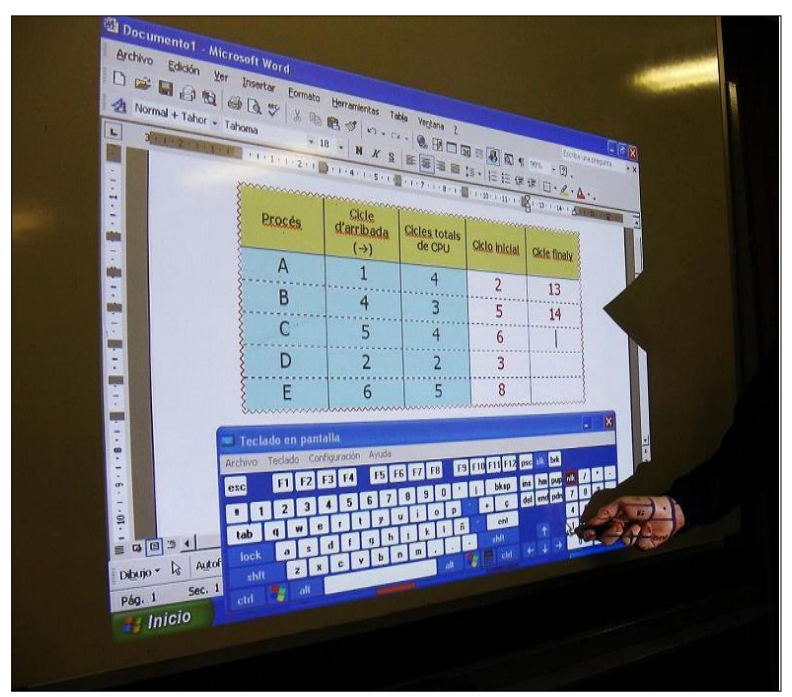

Figura 1: Teclado da Lousa Digital Interativa Portátil

Fonte: [4]

A Lousa Digital é um dispositivo de entrada de dados, assim como um mouse e, ao mesmo tempo, de saída de dados, como a tela, em um tamanho suficiente para a comunicação com toda a turma. Além de todos os softwares que rodam no computador, a Lousa Digital disponibiliza algumas ferramentas digitais e midiáticas, como: escrita em espessuras e cores diferentes, reconhecimento de formas geométricas e escritas, gravação das construções realizadas na aula, ferramenta de cortina, ferramentas de medição na tela (régua, esquadro, compasso), sons, imagens, uso de outros softwares.

Todas essas potencialidades tem sido alvo de investigações para o seu uso como instrumento de ensino.

\subsection{A Lousa Digital no ensino}

$\mathrm{Na}$ fundamentação da pesquisa revisamos pesquisas que trabalharam com uso da Lousa Digital em situações de ensino para melhor enquadrar as nossas análises. Os primeiros estudos objetivam avaliar até que ponto os potenciais da tecnologia da Lousa Digital como uma possível contribuição para o ensino e os impactos que poderiam ter sobre a aprendizagem dos alunos [5]. Postulavam que mudanças pedagógicas dos professores seriam necessárias para que o uso da Lousa Digital, chamada de quadro interativo, provocasse mudança na aprendizagem.

Para avaliar possíveis mudanças pedagógicas com o uso da Lousa Digital, Glover e Miller [5] escolheram uma escola, do Reino Unido, caracterizada como incentivadora e bastante elogiada quanto ao ensino e aprendizagem com uso de novas tecnologias. Quando se trata de verificar a percepção dos professores quanto a mudanças pedagógicas com o uso da Lousa Digital, 23\% dos professores disseram perceber um aumento considerável na utilização de recursos digitais e da internet, revelando que uma das motivações era por estar próximo ao quadro em frente aos alunos e pela disponibilidade de uma variedade de recursos.

Nesta pesquisa, o enfoque sobre interatividade já presente na Lousa Digital, dita interativa, nos remete às questões de uso e potencialidades das ferramentas da Lousa Digital para o ensino. Surgem, assim, várias dúvidas quanto às interações que são ou não favorecidas em relação aos conteúdos matemáticos, especificamente, e o potencial interativo das ferramentas da Lousa Digital no ensino-aprendizagem.

No desenvolvimento de ferramentas que contribuíssem para potencializar a interatividade em sala de aula, Miller et al [6] identificaram que os aspectos interativos da Lousa Digital estavam relacionados aos estágios de interatividade: o suporte didático, o interativo e o aprimoramento interativo. Ao identificar em qual estágio o professor poderia ser enquadrado no momento da aula, podiam gerar estratégias para apoiá-lo no desenvolvimento das habilidades interativas, contribuindo para uma maior mobilidade entre os estágios de interatividade. Essas estratégias eram transformadas em ferramentas para a sala de aula, promovendo uma maior integração entre as ferramentas da Lousa Digital e o professor. Os estágios de interatividade contribuíram para interpretarmos as ações do professor em sala de aula, a partir da identificação do nível de uso das ferramentas da Lousa Digital.

Para auxiliar na utilização da linguagem interativa da Lousa Digital, Nakashima e Amaral [7] propuseram cinco indicadores didático-pedagógicos: interatividade, flexibilidade/multilinearidade, conectividade, qualidade das informações e dos conteúdos e convergência de linguagens. Nessa pesquisa, a questão fundamental era descobrir como a linguagem interativa, presente na Lousa Digital, poderia ser utilizada para a elaboração de práticas pedagógicas.

Nas pesquisas com o uso da Lousa Digital, verificamos a necessidade de estudos que considerem as situações de uso no ensino, nas quais as interações com o uso 
da ferramenta sejam analisadas, que também sejam possíveis avaliações de como ocorrem as interações com vários recursos disponíveis, seus impedimentos e potencialidades. Também a possibilidade de verificar se os professores, de posse dessas ferramentas, conseguem simular situações reais trazidas para a sala de aula, ou mesmo como articulam ou não o saber matemático com o uso da Lousa Digital.

\subsection{A Lousa Digital no ensino da matemática}

Para revisão da literatura sobre uso da Lousa Digital no ensino da matemática analisamos a pesquisa de Vicente e Melão [8], realizada em Portugal, num contexto em que os recursos de Lousa Digital vinham crescendo e poucos estudos apontavam obstáculos e características para um uso eficaz desta ferramenta na sala de aula. No estudo, houve preocupação em avaliar a expectativa dos professores quanto à possibilidade do incremento da tecnologia da Lousa Digital, buscando contribuir para uma reflexão que potencialize o uso mais eficaz desse instrumento.

No sentido de analisar a situação das escolas e dos professores, que na atualidade se defrontam com esta situação de mudança e, consequentemente, com o processo de adoção de novas metodologias de ensino, pretendeu-se, com o estudo, analisar a forma de adoção da Lousa Digital, chamada de quadro interativo (QI), pelos professores na sala de aula. A pesquisa realizou-se por meio do estudo de casos múltiplos, na cidade da Guarda, em Portugal, em cinco escolas.

Os resultados mostraram que o número de Lousas Digitais nas escolas pesquisadas era reduzido. As cinco escolas pesquisadas possuíam um total de 18 Lousas Digitais. Dez professores, de um total de 23, já tinham usado a Lousa Digital e, em três das cinco escolas, o uso daquela ferramenta era bastante reduzido. Como resumo dos resultados, foi verificado que não ocorreu uma preocupação em preparar os professores para usar a Lousa Digital no ensino da matemática, advindo, portanto, da falta de formação, segundo os autores da pesquisa, problemas relativos à gestão daquele recurso pedagógico. Consequentemente, foram detectados, também, problemas quanto à frequência de uso e à falta de exploração dos potenciais da Lousa Digital. Pela entrevista com um coordenador de matemática e pela interpretação dos questionários, os pesquisadores verificaram que a possibilidade de uso de vários recursos digitais simultaneamente e a motivação para explorar conteúdos complexos de maneira mais atrativa e visual proporcionaram o desejo de uso da Lousa Digital por parte dos professores. A falta de pessoal técnico e de equipamento, entretanto, constituía um entrave ao uso. Foi destacado também pelos sujeitos da pesquisa que, antes mesmo de se fazer a inclusão da Lousa Digital na sala de aula, projetos que valorizem os estudos e práticas com o uso das ferramentas devem ser considerados fundamentais.

O fato de se analisarem os recursos digitais mais usados nos traz a possiblidade de relacionar, em nossa pesquisa, os recursos digitais e a contribuição ou não deles para as interações com o saber matemático. Tentamos compreender melhor como se dá a interação dos recursos da Lousa Digital com o ensino de matemática. Boa parte das pesquisas citadas aponta para questões relativas às qualidades da Lousa Digital e a possibilidade de ganho na apresentação dos conteúdos. Todas, no entanto, parecem corroborar com a ideia de que a disponibilização da ferramenta não constitui garantia de "melhor ensino". Precisamos, portanto, analisar os porquês da preferência pelo uso da ferramenta da Lousa Digital, em detrimento do quadro "estático", o que essa prática auxilia no ensino da matemática e quais são os diferenciais.

A pesquisa de Miller et al [9] tenta se diferenciar de outras no contexto de benefícios da tecnologia do uso da Lousa Digital para o ensino. Foca nas mudanças das competências pedagógicas necessárias quando se faz uso da Lousa Digital no ensino da matemática. Para esse propósito tenta investigar como foram efetivamente usadas as Lousas Digitais no ensino da matemática. Seus objetivos principais foram: determinar as características de uso da Lousa Digital durante a atividade de sala de aula; identificar as técnicas de ensino usadas; verificar como o aprendizado foi reforçado; determinar os conceitos desenvolvidos durante a atividade. Foram registradas, ainda, as linhas de tempo e as sequências de atividades de cada lição de matemática, bem como, as questões de gestão da sala de aula.

Fizemos um destaque em um dos resultados dessa pesquisa que colaborou com a análise das interações docentes no ensino da Matemática com uso da Lousa Digital. Foram observadas técnicas de "manipulação" das ferramentas da Lousa Digital, postuladas pelos autores da pesquisa, caracterizadas como maneiras de utilizar os recursos da Lousa Digital. Nos estudos de Miller et al [9], foram então observadas seis manipulações básicas, ou as mais comuns, que garantissem um melhor uso da Lousa Digital no ensino da Matemática, exemplificadas e traduzidas em nossa pesquisa como: arrastar e soltar; esconder e revelar; sombreamento de cor e realce; correspondência de itens; movimento ou animação e feedback imediato. Para cada manipulação, citam-se exemplos de atividades que podem ser propostas no ensino da matemática.

No decorrer de nossos estudos, dimensionamos as manipulações a partir dos recursos digitais da própria Lousa Digital associados ao uso de apresentação pronta, uso de apresentação com gestos sobre a lousa, acesso a sites de compartilhamento, zoom de imagem, uso do lápis em cima da apresentação e outros. Tudo foi estruturado e 
analisado após coleta de dados feita pela nossa pesquisa, considerando, ainda, como hipótese a ser considerada, a análise da articulação ou não dessas seis técnicas e o ensino de Razões, Proporções e Grandezas Proporcionais como conteúdos específicos de matemática.

\section{As interações em sala de aula medi- adas pela Lousa Digital}

Wagner [10] considera interação como eventos recíprocos que requerem pelo menos dois objetos e duas ações que, de alguma maneira, se influenciam mutualmente. Ele conclui ainda que o propósito de uma interação de ensino é a de "responder ao aluno de uma forma destinada a mudar o seu comportamento em direção a um objetivo educacional". Por considerar que a prática docente de uma aula envolve não somente as ações e reações diretas entre professor e aluno, mas também a construção e a preparação de atividades diversas que uma aula suporta, é que incluímos a ferramenta tecnológica, no caso a Lousa Digital, como um ator significativo na interação. Num contexto de uso de novas tecnologias, autores ( [11], [12]) relatam como integrantes das interações os sujeitos e objetos, de maneira mais ampla, as interações são caracterizadas como: sujeito(s) - sujeito(s) e sujeito(s) - objeto (s).

As ferramentas digitais atuam fortemente como atores, pois trazem para o contexto de sala de aula, não somente os saberes do professor e do aluno, saberes construídos nos softwares, que por meio do feedback oferecem uma interação do ator (professor ou aluno) com o saber de um outro sujeito. O feedback, por sua vez, nem sempre é premeditado pelo professor ou pelo aluno.

Nesse ponto, são os objetivos traçados pelo professor e as ações sobre o artefato (ambiente) que geram ou não as potencialidades e limitações das interações, ao disponibilizar contato direto, nos mesmos tempo e espaço, mídias diferentes (vídeos, internet, aulas gravadas, imagens, sons). A criatividade e a experiência com o uso das ferramentas do sistema vão possibilitar um crescente nível de interatividade, considerando também a configuração de ferramentas digitais na Lousa que possibilitem as intervenções do professor.

Para melhor construção da análise das interações em sala de aula, com o uso da Lousa Digital, podemos subdividir os agentes nas seguintes categorias: atores, objetivos e meios das interações, tomando as dimensões de análise utilizadas na pesquisa desenvolvida por Lins [13], considerando características das ações docentes em cada uma delas e entre as mesmas.
São considerados atores o professor, as ferramentas da Lousa Digital e aluno ou alunos. Quando identificarmos o ator Lousa Digital, consideramos, na análise, o uso das ferramentas próprias da Lousa e, quando não for ferramenta da Lousa, podemos identificar como recursos digitais diversos. São objetivos de interação: a gestão de recursos, mediação pedagógica e mediações didáticas.

Os meios que, nesta pesquisa, estamos considerando para análise das interações são as ferramentas da Lousa Digital, os recursos digitais diversos (apresentações, animações, hardwares, som, imagem) e outros recursos didáticos não digitais. Dessa forma, tentamos analisar como se articulam, ou não, essas categorias, diante de objetivos de ensino, sendo eles explícitos ou não. Em nossa pesquisa, tentamos então analisar questões que podem contribuir para um melhor entendimento e destaque nas limitações e possibilidades da prática docente: a) Quais interações são mais ou menos estimuladas? b) Como se articula a interação professor-lousa com o conteúdo específico trabalhado pelo professor nas suas possibilidades e limitações? c) Quais artifícios didáticos e ferramentas se destacam, ou não, com o uso da Lousa Digital? d) Quais interações são mais ou menos favorecidas?

Com tais questões é essencial discutir a mediação permitida pela tecnologia do saber matemático.

\section{0 saber matemático em foco}

Para Pais [14], a Educação Matemática é uma ciência com características e estruturas específicas, com dimensões subjetivas e objetivas. Para construções lógicodedutivas presentes na matemática, tenta-se, num contexto próprio, elaborar uma visão formal e global dos fenômenos que nos rodeiam, explorando, investigando, gerando conjecturas e hipóteses, testando padrões e relações. Essa forma de fazer ciência se diferencia do conhecimento matemático por estar diretamente relacionado às questões cognitivas de aprendizagem. Ao analisar a prática do professor de matemática em sala, o foco está direcionado aos processos de ensino e às propostas didáticopedagógicas.

Quando o professor faz uso da Lousa Digital como ferramenta tecnológica para o ensino e aprendizagem, seus objetivos estão basicamente relacionados ao saber matemático tratado em sua prática pedagógica, seja com a pretensão de melhorar a forma de apresentação, motivar os alunos ou facilitar o entendimento do conteúdo. Analisamos então a relação entre os meios e as mediações didáticas ocorridas. Para tanto, investigamos no momento do uso da interface da Lousa Digital, como o saber é apresentado, ou, caso sejam utilizados softwares específi- 
cos para o ensino da matemática, como eles são articulados com as ferramentas da Lousa Digital e se valorizam, ou não, as interações.

Uma hipótese a ser considerada no contexto da mídia comercial para o uso das Lousas Digitais interativas é a de que os recursos oferecidos contribuem para propostas de metodologias de ensino que conduzam, com mais eficácia, interações entre professor, aluno e o saber matemático. Nesse sentido, aspectos relativos ao saber matemático são essenciais na análise.

Uma propriedade de proporção comumente usada na regra de três é a de que o produto dos meios é igual ao produto dos extremos. De uma maneira geral, considere a proporção $\frac{\mathrm{y}}{\mathrm{x}}=\frac{\mathrm{y}^{\prime}}{\mathrm{x}^{\prime}}$ ou y : $\mathrm{x}:: \mathrm{y}^{\prime}: \mathrm{x}^{\prime}$, sendo y e x' os extremos, $\mathrm{x}$ e y' os meios, com x e x' não nulos. Ao multiplicar ambos os membros da igualdade por X.X' obtém-se: $\left(x x^{\prime}\right) \frac{\mathrm{y}}{\mathrm{x}}=\frac{\mathrm{y}^{\prime}}{\mathrm{x}^{\prime}}\left(x x^{\prime}\right)$, portanto, $x^{\prime} y=y^{\prime} x$. Essa propriedade pode ser usada para determinar um valor desconhecido entre quatro números de uma proporção, operação a que chamamos de regra de três.

Lima et al [15] afirmam que os problemas envolvendo grandezas proporcionais, geralmente, podem ser resolvidos por um dos três métodos: o método direto; o da redução à unidade e o da proporção, cada um deles com suas particularidade e aplicação convenientes. Porém, em todos eles, admite-se que a relação entre as grandezas é proporcional, e todas as condições do conceito de proporcionalidade são respeitadas.

O método direto só é conveniente em situações para as quais não se exigem cálculos complexos, facilitando assim o seu uso [15]. Por exemplo: Uma pessoa vai à padaria e compra 20 pães por R\$4,50. Quanto pagaria por 50 pães, nesta mesma padaria? A resposta poderia ser dada considerando que 50 equivale a 2 vezes e meia o 20 , supondo manter esta mesma relação (razão) para o preço - 4,50 multiplicado por 2 mais metade de 4,50. Teríamos $\mathrm{R} \$ 9,00$ mais $\mathrm{R} \$ 2,25$, totalizando $\mathrm{R} \$ 11,25$. São situações que caracterizam-se como de estruturas multiplicativas das quais as razões e proporções fazem parte [16], classificadas como uma proporção simples de quarta proporcional.

Para situações de quarta proporcional, um dos métodos mais utilizados é o da redução à unidade. Considerando-se o exemplo acima, quanto a pessoa pagaria por um pão? No exemplo, basta dividir 4,50 por 20 , que resulta em 0,225. Logo, um pão custa 0,225 reais, portanto, 50 pães custariam 50 vezes 0,225 , resultando em 11,25, ou seja 11,25 reais, podendo os cálculos ser montados na seguinte estrutura [15].

\section{Quantidade de paes (unidade)}
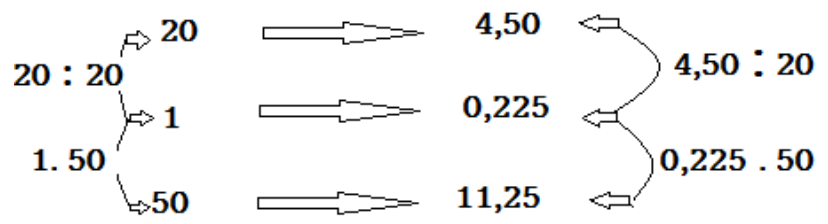

Figura 2: Esquema para uso do método da redução à unidade

Fonte: [15] apud [21], p. 50

Quanto ao método da proporção, podemos chamar de x o preço desconhecido de 50 pães e montar uma regra de três, depois de verificada a proporcionalidade das grandezas, a quantidade de pães e o preço. Temos que $20: 50:$ : 4,50 : x. Na representação de razões proporcionais tem-se $\frac{20}{50}=\frac{4,50}{\mathrm{x}}$. Podemos usar, então, a propriedade de que o produto dos meios é igual ao produto dos extremos, logo $20 x=4,50 \times 50$. Sendo assim, $x=\frac{4,5 \times 50}{20}$, resultando para $\mathrm{x}$ o valor de 11,25 .

Podemos destacar que ao tratamos de razão e proporção em sala de aula, as possibilidades de explorar os saberes matemáticos prévios dos alunos pode favorecer e estimular a construção de propostas de ensino com uso de novas tecnologias. Atividades em que os alunos interajam mais entre eles e a turma exemplificam situações que promovam o debate no grande grupo, com propostas de soluções coletivas, com mediação do professor.

\section{Teoria da Atividade}

Encontramos na Teoria da Atividade, proposta por [17], uma contribuição à análise da atividade docente. Para o teórico, na atividade humana há uma composição complexa de elementos que a constituem e que podem ser categorizados dentro da relação de mediação entre sujeito e receptor. Esta relação de mediação, para Leontiev, é a atividade humana e os elementos que a constituem podem ser representados pelo objetivo geral da atividade (motivo), pelas ações e operações. Entender os motivos, ações e o desenvolvimento das atividades nos permite compreender todas as interações que ocorrem.

Segundo Lins [13], "Um objeto pode ser considerado uma ferramenta, num certo momento do sistema de atividade; num outro instante, pode ser considerado o próprio objeto da atividade ou o produto dessa atividade". Consideramos então investigar entraves, limitações e potencialidades no uso das ferramentas da Lousa Digital, como escrita, toque e articulação ou não com objetivos de ensino. Em relação à manipulação do objeto pelo sujeito, as atividades também são afetadas pela "experiência" do sujeito sobre as ações que pretende realizar num 
sistema de atividades. Estar de posse da ferramenta não garante o cumprimento das metas. Talvez, por esse motivo, a investigação sobre as interações, com o uso dessa ferramenta, poderia contribuir de alguma forma, para elucidar algumas questões relativas às limitações ou potencialidades da atividade.

Pretendemos investigar as interações com o uso do artefato que possa, de alguma maneira, fazer convergir para a sala de aula um contexto de integração de mídias (vídeos, som, imagens), manipulações, representações, transformações, etc. Tentamos compreender as interações mediadas pela tecnologia, mas também os meios e motivos que colaboram ou não para que aconteçam.

\section{Metodologia}

Para investigar a atividade docente com o uso da Lousa Digital, propusemos um estudo de caso, pautado na análise de conteúdo das interações docentes. O uso da Lousa Digital Interativa ainda é recente e, por isso, buscamos analisar a prática docente com o uso da Lousa por um profissional com significativa habilidade com o instrumento, a fim de entender as potencialidades da tecnologia em foco. Como estudo exploratório, decidimos analisar uma situação real de sala de aula que se configurasse um bom usuário da Lousa Digital. Nesse sentido, optamos por utilizar a metodologia de estudo de caso.

Pelos motivos acima expostos, buscamos um referencial metodológico que fosse capaz de captar satisfatoriamente os elementos complexos e simultâneos que compõem a atividade docente em sala de aula. Necessitamos inicialmente de um referencial que nos apoiasse na análise da filmagem e nos permitisse um maior rigor na coleta de dados. Para uma melhor discussão dos dados coletados, buscamos uma análise que, além de qualitativa, nos permitisse uma visão quantitativa e estruturada dos dados. Optamos, portanto, por uma análise de conteúdo que realizasse uma análise qualitativa pautado também em uma análise estatística dos dados categorizados. Ao destacarmos as interações ocorridas entre professor, turma e saber matemático, pela Lousa Digital, a partir da filmagem da aula (utilizada como documento), propusemo-nos a analisar a atividade docente com o uso do meio: a Lousa Digital.

\subsection{Sujeitos}

O sujeito escolhido foi um professor de matemática que já faz uso da Lousa Digital. Para a escolha do sujeito, em um primeiro momento, foi realizada, via telefone, email, uma consulta com professores que tivessem boa experiência no uso da Lousa, indicados por contatos pessoais e/ou profissionais do pesquisador [18], o que facilitou a procura de sujeitos que pudessem fazer parte da pesquisa. No processo de escolha de voluntários, procuramos sempre verificar a destacada experiência do profissional com o uso da Lousa Digital. Também nos informamos se a escola na qual o profissional lecionava possuía a Lousa Digital em sala de aula, além de solicitar a permissão do professor para que fosse filmado. A escola de onde o sujeito foi selecionado está situada na região metropolitana do Recife e possui Lousa Digital há pelo menos cinco anos.

\subsection{A Coleta de Dados}

Culminamos, enfim, com a filmagem de uma aula sobre Razão, Proporção e Grandezas Diretamente e Inversamente Proporcionais, em uma turma do $7^{\circ}$ ano do Ensino Fundamental. A fundamentação sobre o saber matemático presente na pesquisa foi, portanto, realizada póscoleta.

Tivemos o cuidado de procurar minimizar as interferências provocadas pelas filmagens na naturalidade das aulas. E, para que o professor voluntário se sentisse o mais confortável possível em sua atividade docente, em uma situação particular de ensino, optamos por deixar, a encargo do próprio professor, a escolha tanto da turma quanto dos conteúdos matemáticos a serem observados e trabalhados respectivamente durante a pesquisa.

Registramos 37 minutos e 38 segundos da aula do professor, a fim de captar as interações com o uso da Lousa Digital. A câmera esteve focada no professor e na Lousa Digital. A sala foi preparada antecipadamente com a câmera em um local previamente estabelecido, para que afetasse o mínimo possível o ambiente. O professor utilizava um microfone a fim de não perdermos a fala dele, e o som da sala também foi áudio gravado.

\subsection{Análise de Dados}

A análise de dados foi realizada por meio de uma primeira descrição da aula, seguida de uma análise de conteúdo das interações que o professor participa. A primeira etapa foi considerada de grande importância para familiarizar o pesquisador com os dados, e essencial para a análise de conteúdo, a fim de melhor delimitar as unidades de registro e as categorizações possíveis.

A unidade de registro considerada na pesquisa foram as interações que envolvessem o professor e a turma, com objetivos bem delimitados, mediados ou não pelo uso da Lousa Digital.

Para registrar e organizar cada interação um protocolo escrito com a descrição da cena, os atores e o feedbacks, intervalo de tempo na filmagem (localização) e descrição literal da fala foi feito. 
Nos 37 minutos e 38 segundos da aula do professor foram identificados 130 interações. Com base em Lins [13], tomamos as seguintes dimensões: objetivos docentes da interação, os atores envolvidos na interação, a lateralidade das interações e os meios utilizados nas interações. A partir de uma primeira descrição dos dados, percebemos a necessidade de incorporar as dimensões relativas ao conteúdo matemático e a sua abordagem, nas dimensões: conteúdo e exemplos utilizados.

Os dados foram tratados com o uso do software Nvivo 8 ([19]).

Assim como em Lins [13], a interação com o saber matemático foi reconhecido, a partir dos objetivos da interação, que a delimita, e não é colocado como um dos atores na interação. Destacamos uma descrição das interações entre os atores:

- Professor-Aluno;

- Professor - Turma;

- Aluno - Professor;

- Turma-Professor;

- Professor - Lousa Digital;

- Professor - Lousa Digital - Aluno;

- Professor - Lousa Digital - Turma;

- Aluno - Lousa Digital - Professor;

- Turma - Lousa Digital - Professor;

- Outras.

Quanto à lateralidade, utilizamos as mesmas categorias de Lins [13]: Unilateral; Bilateral e Multilateral. As unilaterais aquelas com um único emissor e os demais atores são passivos. As bilaterais há emissor e receptor, ambos ativos e com troca de função. E as multilaterais em que diversos atores interagem entre si.

Em relação aos objetivos das interações, utilizamos a classificação das atividades docentes: Mediação didática, Mediação Pedagógica, Gestão de Recursos, Outras.

Devido ao nosso interesse específico nas interações que visam o conteúdo matemático, subcategorizamos as mediações didáticas:

- Resgatar o Conteúdo;

- Estabelecer objetivo da aula;

- Apresentar um conceito, procedimento, etc;

- Propor situação-exemplo;

- Resolver um problema;

- Explicar uma dúvida.

Essa subcategorização foi feita após a descrição dos dados, com base nos mesmos.

Em relação aos meios de interação, tomamos por base a discussão da literatura sobre a Lousa Digital em sala de aula, adaptações das categorias tomadas em [13], e uma revisão das categorias durante a análise.
- Fala ou/e gestos;

- Recursos da Lousa Digital: preocupamo-nos em identificar momentos em que configurassem o uso de Lousa Digital, durante a aula, e as subcategorias ficaram assim definidas: Acesso a sites de compartilhamento; Uso de apresentação pronta; Zoom na Imagem; Apresentação com gestos sobre a Lousa Digital; Uso do lápis em cima da apresentação; Outros.

- Outros: quaisquer outros recursos, usados durante a aula, que não se enquadram nos anteriores.

Os conteúdos matemáticos foram identificados pelo pesquisador, nos dados, com ênfase em Razão e Proporção, classificados em: Razões; Razões Especiais; Propriedades das Proporções; Grandezas Diretamente Proporcionais; Grandezas Inversamente Proporcionais; Relação entre Medidas; Grandezas e suas Medidas; Tabela; Variável $\mathrm{x}$.

Os exemplos utilizados no contexto da aula foram também categorizados em: Distância percorrida; Densidade; Escala; Maquete; Receitas de bolo; A pintura na parede; Velocidade Média; Corredor de Arquimedes (quatro exercícios de proporção que o professor mudou apenas os valores).

\section{Discussão dos Resultados}

Um recorte dos dados da pesquisa serão discutidos neste artigo. Partimos porém de um brevíssima descrição da aula observada, para situar o leitor.

\subsection{Uma rápida descrição da aula}

Na sala, a Lousa Digital estava ligada e conectada ao computador, com acesso à Internet, e ao projetor, o professor inicia a aula comentando com os alunos as atividades que havia realizado anteriormente e o que vai dar continuidade à aula. Então, ele disponibiliza, na Lousa Digital, uma apresentação previamente preparada, por ele mesmo, em um site de compartilhamento de uma empresa parceira da escola. A apresentação foi montada em uma ferramenta de apresentação, muito próximas às do PowerPoint. Durante a apresentação, o professor mantém disponíveis e acessíveis na tela, ferramentas de Lousa Digital, como: a função caneta; cores; cortina; salvar.

$\mathrm{Na}$ parte inicial da aula, o professor utiliza a Lousa Digital para trazer conteúdos e exemplos , porém quando interage com o aluno a partir de ideias dos alunos ou no resgate ao conteúdo, a interação é pautada no uso apenas de gestos e falas.

O professor utiliza a Lousa no sentido de trazer problemas práticos para sala de aula, em uma apresentação com problemas escritos e poucas imagens. A Lousa Digital é utilizada nessa fase como uma tela de projeção. 
$\mathrm{Na}$ apresentação montada pelo professor, são deixadas lacunas com valores ocultos que vão surgindo após toques na tela durante a explicação. Em alguns casos, o professor escreve na Lousa Digital, usando a função lápis.

A partir de certo momento, quando vê a necessidade de utilizar um quadro negro para fazer contas a partir da dúvida do aluno, o professor abre a ferramenta da página em branco e faz uso da Lousa escrevendo sobre ela. O professor prefere escrever sobre uma apresentação em branco, como em um quadro estático, como está exemplificado na figura 3 .

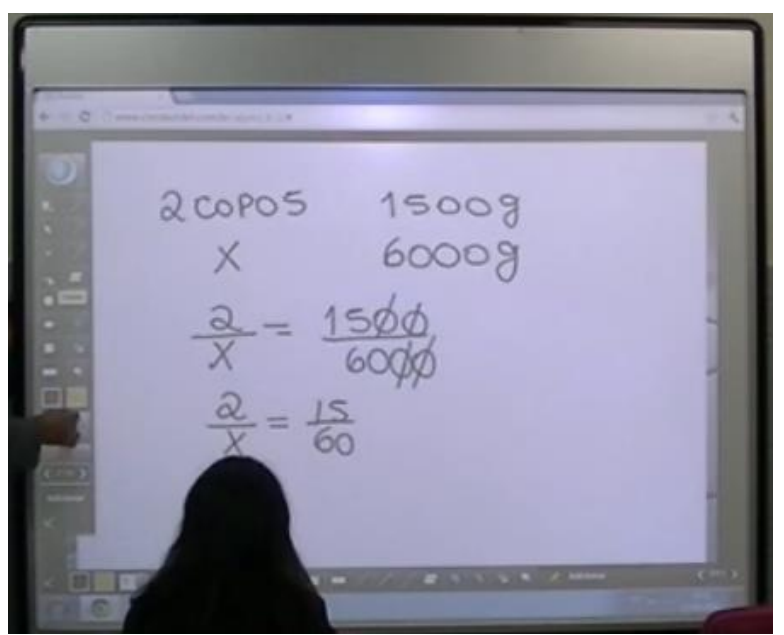

Figure 3: Professor escreve sobre tela em branco

Após certo momento da aula, o professor se sente mais livre para usar e escrever sobre a própria apresentação, em uma interação mais direta entre o conteúdo preparado e a dúvida do aluno.

Durante toda a aula, a quantidade de exemplos trazidos é grande.

Na parte final da aula, o professor apresenta nova atividade na Lousa Digital: um exercício cujo objetivo era a obtenção da quarta proporcional, apresentado em forma de animação, esta última chamada de Corredor de Arquimedes. Nele, o aluno deve indicar o pote com a quantidade certa. São dados três valores e deve ser obtido o quarto valor que, neste caso, é a quarta proporcional.

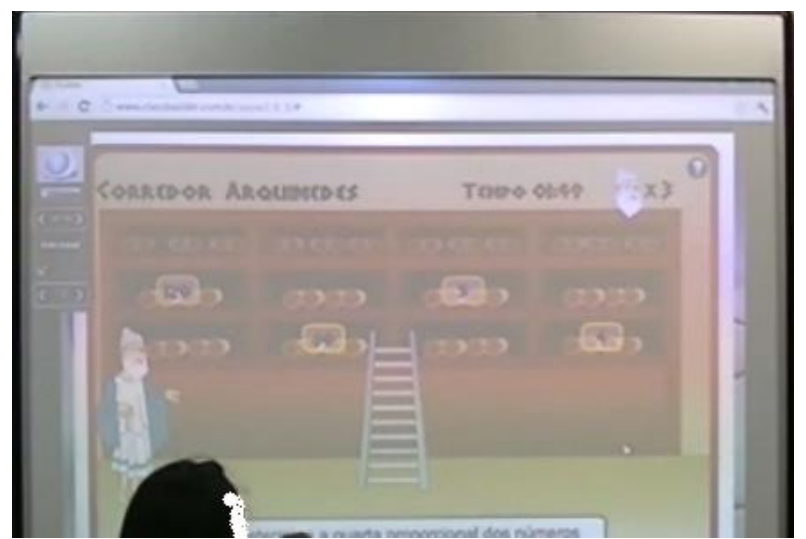

Figura 4: Exercício em animação na Lousa Digital para calcular a quarta proporcional

Os alunos foram orientados a não tocar na Lousa Digital. Deveriam realizar os cálculos no caderno e aquele que já tivesse obtido uma resposta para o problema, iria ao teclado/mouse e marcaria o valor na Lousa Digital. No decorrer da aula, com alunos agitados e mais de um desejando responder, o professor passa a controlar a ida ao teclado.

\subsection{Atores e lateralidade nas interações}

Para verificarmos a hipótese sobre o favorecimento nas interações de ensino na aula observada, verificamos na análise dos dados que a Lousa Digital participa como ator, de uma maneira geral em 55,4\%. Considerando especificamente as interações do tipo Professor - Lousa Digital - Aluno e Professor - Lousa Digital - Turma, aproximadamente $45,4 \%$ das interações de sala de aula, o que caracteriza boa parte das ações em sala de aula com a Lousa Digital como ator (Gráfico 1).

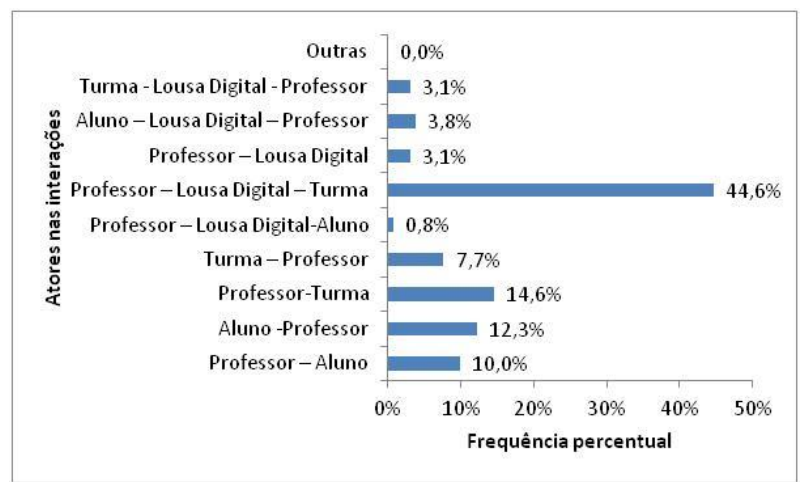

Gráfico 1: Frequências de interações por atores

As ações docentes, mesmo para um professor experiente com o uso da Lousa Digital, observa-se que como qualquer instrumento de ensino, o uso da Lousa Digital não faz parte da totalidade da aula. A ação docente se faz configurar na aula, também nas interações com aluno ou turma, pautada na oralidade da explicação do professor, 
sem uso de Lousa Digital em aproximadamente 24,6\% das interações observadas.

Percebemos que mesmo diante de ferramenta tecnológica e experiência no uso da Lousa Digital, o professor usa o discurso para elucidar dúvidas e manter os alunos atentos à explicação. Estas atitudes são comparadas ao uso de um quadro estático em uma aula expositiva. A interatividade exige uma participação ativa dos sujeitos envolvidos na comunicação ([20];[13]). De posse da Lousa Digital seria necessário, além do uso do recurso por parte do professor, ações que levassem em consideração a maior participação da turma; operações que promovessem um ambiente interativo. Apenas a ferramenta não garante interatividade.

Nesse sentido, foram constatadas poucas interações que parte do aluno ou da turma, do tipo Aluno - Lousa Digital - Professor ou Turma - Lousa Digital - Professor, com aproximadamente $6,9 \%$ de interações observadas na aula. Precisamos considerar a hipótese do professor não ter planejado para a aula analisada este comportamento por parte dos alunos.

\subsection{Objetivos de interações}

A aula observada concentrou grande parte do tempo em mediações didáticas. $\mathrm{O}$ uso da Lousa com uma aula planejada, parece ter sido primordial para que a aula de fato tivesse seu foco no trabalho didático. Poucas interações foram observadas nas quais o professor precisou realizar gestão dos recursos, na preparação para o que iria realizar durante a aula (apenas 5,4\% das interações). O professor durante a aula apresentou um bom conhecimento dos recursos da Lousa Digital e seus possíveis feedbacks. Este fato foi observado como um facilitador nas ações e operações desenvolvidas em sala de aula. As questões internas ao professor sobre como fazer e o que fazer no uso dos recursos colaborou com o tempo de aula destinado a outras ações. Porém, não foi percebido preparação para usar a Lousa Digital em situações inesperadas durante a aula.

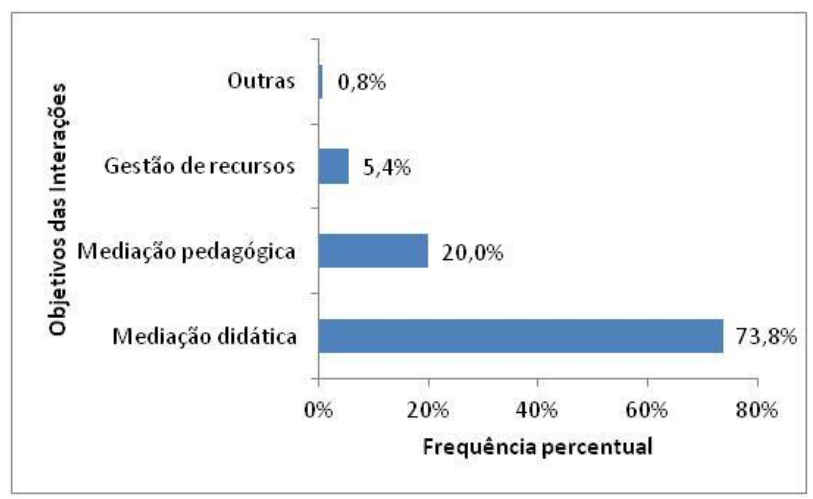

Gráfico 2: Percentual dos objetivos das interações.
Isto mostra que com a habilidade do professor com a lousa digital foca essencialmente no que ele consegue preparar e disponibilizar o material no decorrer das mediações.

Nas mediações didáticas, construídas teoricamente, foram assim re-categorizadas a partir dos dados: Explicar ou comentar dúvida; Resolução de problema; Propor situação problema; Apresentação de conceito ou procedimento; Estabelecer objetivo da aula; Resgate de conteúdo.

O gráfico a seguir apresenta o percentual das 96 interações categorizadas como sendo de mediação didática, segundo as subcategorias.

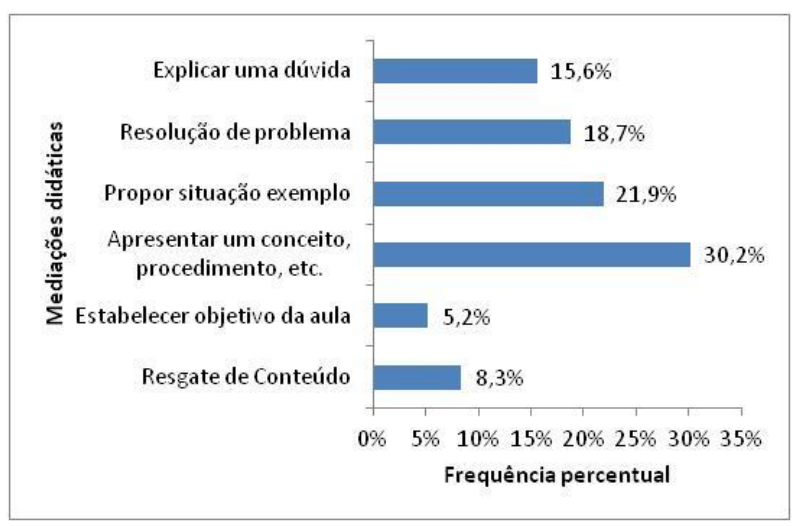

Gráfico 3: Percentual das subcategorias das mediações didáticas.

A concentração maior da aula é no trazer elementos prontos, porém, mais que $34 \%$ das mediações didáticas envolvem uma troca mais intensa entre professor e aluno.

O professor explorou basicamente os conteúdos de razões, proporções, grandezas diretamente proporcionais e grandezas inversamente proporcionais. Porém, outros conteúdos subjacentes são trabalhados pelo professor: grandezas e medidas; relação entre medidas; tabelas; cálculo de variável $\mathrm{x}$.

\subsection{Meios usados nas interações}

Percebemos que mesmo diante de ferramenta tecnológica e experiência no uso da Lousa Digital, o professor usa o discurso para elucidar dúvidas e manter a turma atenta a sua explicação. Os dados confirmam a fala e gestos, sem uso de recurso da Lousa Digital, em aproximadamente $38,5 \%$ das interações observadas na aula. Estas atitudes são comparadas ao uso de um quadro estático em uma aula expositiva.

Quanto aos recursos da Lousa Digital nas interações da aula observada percebemos que o recurso de usar apresentação com gestos sobre ela foi o mais presente, em aproximadamente $51,5 \%$ das interações. Quando o professor fez uso da Lousa Digital, já preparou antecipadamente a apresentação para associar como recurso da 
Lousa Digital. Os estudos de [6] e [21] sugerem que as intervenções do professor para potencializar as ferramentas da Lousa Digital estão relacionados a variedade de recursos digitais.

O professor usou na Lousa Digital apresentações prontas, como tabelas, imagens, textos de problemas em aproximadamente $28,8 \%$ das interações. $\mathrm{O}$ fato de usar a Lousa Digital como ferramenta de ensino potencializou o uso de recursos digitais, no caso as apresentações prontas, como observado nos dados, num total de aproximadamente $80,3 \%$ das interações com uso da Lousa Digital.

\subsection{Analise dos resultados dos cruzamentos de dados}

O cruzamento dos tipos de interações de mediações didáticas (em suas subcategorias) com os meios mostram o seguinte resultado.

Quando observamos os meios usados nas interações de sala de aula nos objetivos de interação, tal como sistematizados na tabela 1 abaixo, podemos destacar que, quando ocorre mediação didática, o recurso mais usado na aula observada, com aproximadamente $71,8 \%$ dessas interações, são os recursos da Lousa Digital. As falas e gestos sem uso da Lousa Digital nas mediações didáticas ocorrem em $22,7 \%$ das interações.

\begin{tabular}{ccccc}
\hline & $\begin{array}{c}\text { Gestão de } \\
\text { Recursos }\end{array}$ & $\begin{array}{c}\text { Mediação } \\
\text { Didática }\end{array}$ & $\begin{array}{c}\text { Mediação } \\
\text { Pedagogica }\end{array}$ & Outros \\
\hline Falas e gestos & $0 \%$ & $22,7 \%$ & $90,8 \%$ & $0 \%$ \\
Outros & $0 \%$ & $0,5 \%$ & $0 \%$ & $0 \%$ \\
Recursos da Lousa Digital & $70,3 \%$ & $71,8 \%$ & $4,6 \%$ & $100 \%$ \\
Recursos Digitais Diversos & $29,7 \%$ & $5,0 \%$ & $4,6 \%$ & $0 \%$ \\
\hline Total & $100 \%$ & $100 \%$ & $100 \%$ & $100 \%$ \\
\hline
\end{tabular}

Tabela 1: Os meios nos objetivos de interações

Podemos então dizer que, quando há o objetivo de trabalhar conteúdos na sala de aula observada, o apoio do docente nos recursos da Lousa Digital foi fundamental.

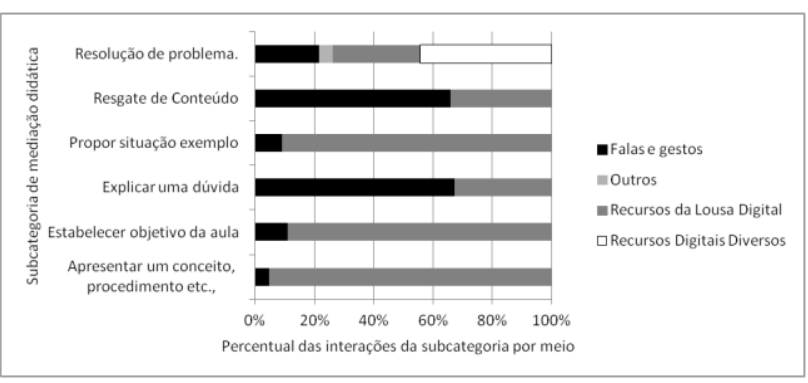

Gráfico 4: Os meios nos objetivos de mediações didáticas

Ao destacarmos os meios nas medições didáticas, sistematizadas no gráfico 4 acima, podemos verificar que os recursos da Lousa Digital na apresentação de conceitos ou procedimentos são usados em aproximadamente 95,3\% das interações que buscam a apresentação de conceitos ou procedimentos em mediações didáticas, que correspondem, na aula investigada, a quase a totalidade das interações com tal objetivo. A fala e os gestos sem uso da Lousa Digital, na apresentação de conceitos ou procedimentos, aparecem com apenas $4,7 \%$ das interações observadas. Podemos ainda enfatizar o recurso da Lousa Digital no estabelecimento do objetivo da aula, ou para propor situações- exemplo respectivamente em aproximadamente $88,9 \%$ e $90,9 \%$ dessas interações. Em resumo, nas seis categorias de mediações didáticas, em metade delas o uso da Lousa Digital tem ocorrência superior a $88 \%$.

Observa-se que nas interações em que não há uma situação pronta, isto é, preparada previamente pelo professor para uso com a Lousa Digital, a Lousa é pouco usada. Situações tais como quando o professor explica uma dúvida ou resolve um problema.

A fala e os gestos sem uso de recursos da Lousa Digital aparecem para explicar uma dúvida, com aproximadamente $67,3 \%$ e, para resgate de conteúdo, ocorre em $65,8 \%$. Podemos observar, então, que na resolução de problemas, a fala e os gestos ou o uso de recursos da Lousa Digital são meios usados em aproximadamente metade das interações. Um destaque pode ser feito para o uso de recursos digitais diversos, no caso o teclado, na resolução de problemas, com aproximadamente 44,2\%.

Especificamente nas ações com objetivos de mediações didáticas respectivamente de apresentar conceito ou procedimento, estabelecer objetivo das aulas e propor situações exemplos o uso de recursos da Lousa Digital aparece em 95,3\%, 88,9\% e 90,9\%. Estes dados mostram que o uso da Lousa Digital, nos objetivos de mediação didática, foi bastante favorecido. Este fato corrobora com [7], na perspectiva de uso da Lousa Digital, o professor tende a proporcionar apresentações de conteúdo com variedade de exemplos e recursos digitais.

Quando observamos, por exemplo, as interações do tipo Professor - Lousa Digital - Turma, em todas as interações, verificam-se $44,6 \%$ de ocorrências. Porém quando o universo corresponde às mediações didáticas as interações do mesmo tipo correspondem a aproximadamente $58,3 \%$. O que corrobora com a hipótese de que na aula observada o uso da Lousa Digital foi potencializado quando ocorreram interações de ensino.

Quando analisamos as interações com objetivo mediações didáticas, aquelas em que ocorre apresentação de um conceito, procedimento, etc. a interação Professor Lousa Digital -Turma aparece em 88,9\% deste universo. Observa-se que o professor em boa parte das mediações faz uso da Lousa Digital para interagir com a turma. Outra mediação em que o mesmo tipo de interação surge numa frequência considerável são as relativas às mediações sobre os objetivo da aula, com aproximadamente $88,4 \%$ destas interações. Na aula observada os resultados 
sugerem que para apresentar o conteúdo a Lousa Digital torna-se uma ferramenta fundamental.

A Lousa Digital não aparece como a ferramenta mais usada quando o objetivo de mediação corresponde explicar dúvida, nas interações do tipo Aluno - Professor são $42,7 \%$, praticamente o dobro das interações do tipo Professor-Lousa Digital-Turma, com aproximadamente $21,5 \%$.

Quanto à apresentação do conteúdo e as metodologias de ensino adotadas na aula podemos concluir a partir do cruzamento dos dados relativos a recursos da Lousa Digital sobre potencialidades e limitações dos recursos da Lousa Digital e os conteúdos de razão e proporção.

Quando tomamos como universo as mediações didáticas percebemos que $47,2 \%$ ocorreram em uso de apresentações com gestos sobre ela. Quando o universo corresponde à mediação didática especifica, no caso apresentação de um conceito ou explicar uma dúvida, a apresentação com gestos sobre ela ocorre respectivamente em aproximadamente $61,4 \%$ e $62,3 \%$.

As atividades relacionadas aos conteúdos da aula estão estruturadas na metodologia adotada pelo professor para alcançar os objetivos de ensino. O professor usa os recursos da Lousa Digital para apoiar a fala e os gestos principalmente nos momentos de explicação de conceito ou procedimentos, apontado na apresentação, reforçando com a escrita sobre ela ou usando uma apresentação pronta como tabelas para explorar relações.

\section{Considerações Finais}

$\mathrm{Na}$ pesquisa foi observado que o professor quando usou a Lousa Digital proporcionou inserção dos recursos digitais para estabelecer relações entre os conteúdos de razão e as propriedades de proporção, principalmente, aos cálculos da variável x. Usou a tabela e os valores que aparecem para que os alunos observem como as medidas surgem, comparando e tentando estabelecer relações de proporcionalidade.

Para incentivar interações com a turma na perspectiva de motivação, esclarecimento, e melhor apresentação do conteúdo, e variedade de representações, foram usadas como exemplo: tabelas, textos digitalizados, imagens que podiam ser ampliadas ou reduzidas, exercícios com animação para resolver problema de proporcionalidade com variável $\mathrm{x}$.

Em vários momentos o professor utilizou a Lousa Digital sobre apresentação em branco, como quadro estático para comentar procedimentos. Em outros o professor preocupava-se em escrever sobre apresentação pronta tentando relacionar diretamente o que estava exposto com suas explicações. Neste ponto o uso da Lousa Digital permitiu ao professor melhor explorar o tempo de aula para explicar o assunto, considerando material disponibilizado na apresentação preparado previamente.

O professor usou a apresentação como registro digital que pode ser novamente acessados para retomada da aula. A apresentação pronta pode ser alterada durante a explicação no acréscimo das observações escritas sobre ela. As interações com as mediações didáticas relativas à apresentação de conteúdo ou procedimentos foram introduzidas com gestos sobre ela ou uso de lápis sobre apresentação, zoom na imagem, associados durante a aula. Percebemos a importância de o professor ter a sua disposição material digital pronto à medida que executa sua aula, pois os recursos preparados antecipadamente dão sentido às interações do professor com a turma usando a Lousa Digital. Ao contrário, sendo a Lousa Digital o único recurso para contato com a turma, o professor nesta perspectiva focou a apresentação na fala e gestos e trabalha com Lousa Digital como um quadro estático.

Os recursos de multimídia, sites diversos, vídeos, ou até mesmo um software de matemática para explorar melhor as interações foram pouco usados. Quando não há material digital preparado para ser usado com os recursos da Lousa Digital temos uma limitação na apresentação do conteúdo.

Quando o professor procura inserir na sua metodologia de ensino, diferentes linguagens, uso de recursos midiáticos associados a Lousa Digital, pode-se perceber o desenvolvimento profissional a partir da necessidade da exploração destas novas tecnologias.

Dentre as interações com objetivo de mediação didática, a Lousa Digital foi usada pelo professor na maioria dessas interações, aproximadamente $71,8 \%$. Dentre as interações de mediação didática, observou-se o uso da Lousa Digital em 95,3\% daquela para apresentação de conceitos e procedimentos, $88,9 \%$ das para estabelecer objetivos de aula e $90,9 \%$ das relativas à proposição de exercícios. No ensino de razões e proporções com o uso de recursos da Lousa Digital, ficou evidente que o uso da Lousa permitiu ao professor propor uma boa variedade de exercícios e recursos digitais, em forma de textos, tabelas, exemplos, tentando favorecer a apresentação dos conteúdos relacionados. Na nossa pesquisa o uso da Lousa Digital favoreceu o ensino da matemática em potencializar metodologias de ensino na apresentação dos conteúdos e no uso de recursos digitais. Não foram propostas atividades em que os alunos interagissem diretamente com a Lousa Digital. Algumas ferramentas digitais, como o uso do teclado na Lousa Digital ou a função lápis, precisam ser mais bem estruturadas e articuladas com outros softwares. 
Em relação às interações em sala de aula com a Lousa Digital interativa, foi evidenciado que boa parte passava necessariamente por recursos da Lousa Digital, associado à prática do professor com a Lousa Digital e/ou a disponibilidade da ferramenta na sala de aula no lugar do quadro estático. No mapeamento dos atores envolvidos e o uso da Lousa Digital ficaram evidenciados poucos momentos de interações em que os alunos fazem uso da Lousa Digital.

A pesquisa evidencia o pouco tempo usado na gestão de recursos, correspondente a preparação da aula. Concluímos que a experiência do professor e o uso de recursos digitais preparados previamente contribuíram para aproveitamento eficiente do tempo de aula.

Quanto às interações em sala de aula relacionadas ao ensino de matemática, foi evidenciado que nas mediações didáticas a Lousa Digital é usada pelo professor em grande parte destas interações. Especialmente nas interações com objetivos específicos de apresentação de conceitos e procedimentos, para estabelecer objetivos de aula e na proposição de exercícios.

No ensino de razões e proporções com o uso de recursos da Lousa Digital, ficou evidente que o professor propôs durante o tempo de aula uma boa variedade de exercícios e recursos digitais, em forma de textos, tabelas, exemplos, tentando favorecer a apresentação dos conteúdos relacionados.

\section{Referências}

[1] R. H. R Nakashima; S. F. Amaral. A linguagem audiovisual da lousa digital interativa no contexto educacional. Educação Temática Digital, Campinas, v.8, n.1, p.33-50, dez. 2006. Disponível

em:

<http://lantec.fae.unicamp.br/tvdi/lantec/publica coes/rosaria.pdf $>$. Acesso em: 20/05/2012.

[2] J. Kaput. Technology and Mathematics Education. University of Massachusetts, Dartmouth. In: GROUWS, Douglas A. Handbook of Research on Mathematics Teaching and Learning. National Council of Teachers of Mathematics, Macmillan Publishing Company. 1992.

[3] V. Gitirana. Função Matemática: o entendimento dos alunos a partir do uso de softwares educacionais. In: BORBA, R.; GUIMARÃES, G.. (Org.). A Pesquisa em Educação Matemática: repercussões na sala de aula. São Paulo: Cortez Editora, v. 1, p. 212-240, 2009.

[4] S. F. Marqués. La Pizarra Digital. No prelo.
Disponível

em $<$ http://ardilladigital.com/DOCUMENTOS/TEC NOLO-

GIA\%20EDUCATIVA/TICs/T9\%20PIZARRA \%20DIGITAL/09\%20LA\%20PIZARRA\%20DI GITAL.pdf>. Acesso em 8/11/2011.

[5] D Glover; D.J. Miller. Running with technology: the pedagogic impact of the large-scale introduction of interactive whiteboards in one secondary school. Journal of Information Technology for Teacher Education, v. 10, no. 3. p. 257-276. 2001. Disponível em: $<$ http://www.informaworld.com/smpp/content d $\mathrm{b}=\mathrm{all} \sim$ content $=\mathrm{a} 739086631>$. Acesso em: $10 / 01 / 2012$.

[6] D. J. Miller; D Averis; V. Door; D. Glover. How can the use of an interactive whiteboard enhance the nature of teaching and learning in secondary mathematics and modern foreign languages? Report made to Becta. 2005a. Disonível em: < http://bit.ly/iwbmillerbecta>. Acesso em 15/10/2012.

[7] R. H. R. Nakashima; S. F. Amaral. Indicadores didático-pedagógicos da linguagem interativa da lousa digital. Cadernos de Educação (UFPel), v. 37, p. 1-21, 2010. Disponível em: < http://www.ufpel.edu.br/fae/caduc/downloads/n3 7/15.pdf>. Acesso em: 12/12/2012.

[8] C. Vicente; N. Melão. A adoção do quadro interativo pelos professores de matemática do $3^{\circ}$ CEB: um estudo empírico nas escolas da Guarda. Educação, Formação \& Tecnologias, vol.2 no2; pp. 41-57. 2009. Disponível em: $<$ http://eft.educom.pt/index.php/eft/article/view/ 93/67>. Acesso em: 12/02/2012.

[9] D. J. Miller; D Averis; V. Door; D. Glover. Developing Pedagogic skills for the Use of Interactive Whiteboards in Mathematics. Glamorgan: British Educational Research Association. 2005b. Disponivel em: < <http://www.keele.ac.uk/media/keeleuniversity/f achu

msocsci/sclpppp/education/interactivewhiteboar d/BERA\%20Paper\%20Sep\%202005.pdf>.

Acesso em: 18/08/2012.

[10] E. D. Wagner. In support of the function of definition of interaction. The American Journal of Distance Education, Philadelphia, v. 8, n. 2, p. 6-29, 1994.

[11] T. Anderson. Getting the Mix Right Again: An updated and theoretical rationale for interaction. 
International Review of Research Open and Distance Learning. Athabasca, Canadá, Athabasca University, v. 4, n⿳ 2, ISSN: 1492-3831. 2003. Disponível em: <http://www.irrodl.org/index.php/irrodl/article/v iew/149/230>. Acesso em: 12/04/2012.

[12] M. Moore. Three Types of Interaction. The American Journal of Distance Education, Philadelphia, v3, nº2, 1989.

[13] W. C. B. Lins. Interações em atividades docentes online em ambientes de imersão 3D. Tese (Doutorado em Educação)-Universidade Federal de Pernambuco. CE, Recife, 2010.

[14] L. C. Pais. Didática da Matemática: uma análise da influência francesa. 2. ed. 2. reimp. Belo Horizonte: Autêntica, 2008. (Coleção Tendências em Educação Matemática, 3)

[15] E. L. Lima; P. C. P. Carvalho; E. Wagner; A. C. Morgado. Temas e Problemas Elementares. 2. ed. Sociedade Brasileira de Matemática. Rio de Janeiro, 2006. (Coleção do Professor de Matemática).

[16] G. Vergnaud. El niño, las matemáticas y la realidad: problemas de la enseñanza de las matemáticas em la escuela primária. México: Trillas, 1991.

[17] A. Leontiev. Actividad, Conciencia, Personalidad. Habana: Editorial Pueblo y Educación, edição em Espanhol, 1981.

[18] P. C. de O. Melo. A Lousa Digital no ensino de Razão e Proporção: uma análise das interaçõesInterações. Dissertação (Mestrado em Educação Matemática e Tecnológica) -Universidade Federal de Pernambuco. CE, Recife, 2013.

[19] QSR Internacional. NVivo8. Melbourn- Australia. Software para análise qualitativa e quantitativa de dados, 2008. Disponível em: <http://www.qsrinternational.com>. Acesso em: 12/05/2012.

[20] A. F. T. Primo. Interação mútua e reativa: uma proposta de estudo. Revista da Famecos, n. 12, p. 81-92, jun. 2000.

[21] W. Beeland. Student Engagement, Visual Learning and Technology: Can Interactive Whiteboards Help? 2002. Action Research Exchange 1 (1). Valdosta State University, Valdosca, Georgia - USA. Disponível em: $<$ http://chiron.valdosta.edu/are/Artmanscrpt/vol1 no1/beeland_am.pdf $>$. Acesso em: 10/08/2011. 